\title{
CORRESPONDENCE
}

\section{Plasmids of mycobacteria}

In a recent article, Dam et al. [1] reported the existence of plasmids in Mycobacterium avium-intracellulare isolates from patients with chronic pulmonary mycobacteriosis. It was a pity that they did not provide evidence to substantiate their findings in the form of photographs of either electrophoresis gels or electron microscopic studies. The reference number 5 cited in the text [1] emphasised the methodology for isolation of plasmids from mycobacteria and did not provide details of a $15.3-\mathrm{kb}$ circular plasmid DNA, as mentioned by the authors. Crawford and Bates [2] reported the existence of two plasmids in M. avium-intracellulare pLR strain one as large (with no mention of its molecular size) and the other one as small with a size of $6 \times 10^{6}$ (see Fig. 1 of Crawford and Bates [2]). Based on preliminary findings of hybridisation experiments, Dam et al. [1] are not clear whether the 24-kb DNA is (partially) homologous with either small, large or both plasmids. The authors do not seem to have made any attempt to determine the size and characterisation of other plasmids as they claim to have observed multiple bands in six isolates. It is interesting that Dam et al. [1] were able to demonstrate plasmids in c. $40 \%$ of isolates, as did Crawford and Bates (45\%, 9 of 20 isolates) [2]. The authors say that 24-kb DNA was purified and subjected to electron microscopy and restriction digestion for further confirmation, but later contradict this saying that the restriction map of 24-kb DNA was still under study. Therefore, it is difficult to accept the reported finding because there is no evidence to confirm their observations. Ideally the authors should have carried out a complete study with clear objectives of isolation, identification and characterisation of plasmids from $M$. avium-intracellulare in order to determine their role in molecular mechanisms of pathogenesis, drug resistance, host-parasite relationship or any other related aspect.

We have searched extensively for the presence of any plasmids in various standard laboratory strains of mycobacterial species including $M$. avium-intracellulare and clinical isolates (M. tuberculosis) of high virulence and multi-drug resistance (unpublished data) by the lysis method as described elsewhere [2]. Invariably, in all mycobacterial species tested including laboratory strains and clinical isolates, a band was observed in the region between 9.0 and $23.1 \mathrm{~kb}$ with an approximate size of $18 \mathrm{~kb}$ (Fig. 1). This observation was supported by the in-situ lysis method and electron microscopic studies (unpublished data). This finding was evidenced by an improved method for isolation of supercoiled plasmid DNA (Fig. 2) [3]. The biological significance of this extrachromosomal DNA could not be attributed to either virulence or drug resistance, as its presence was observed in all mycobacterial species.

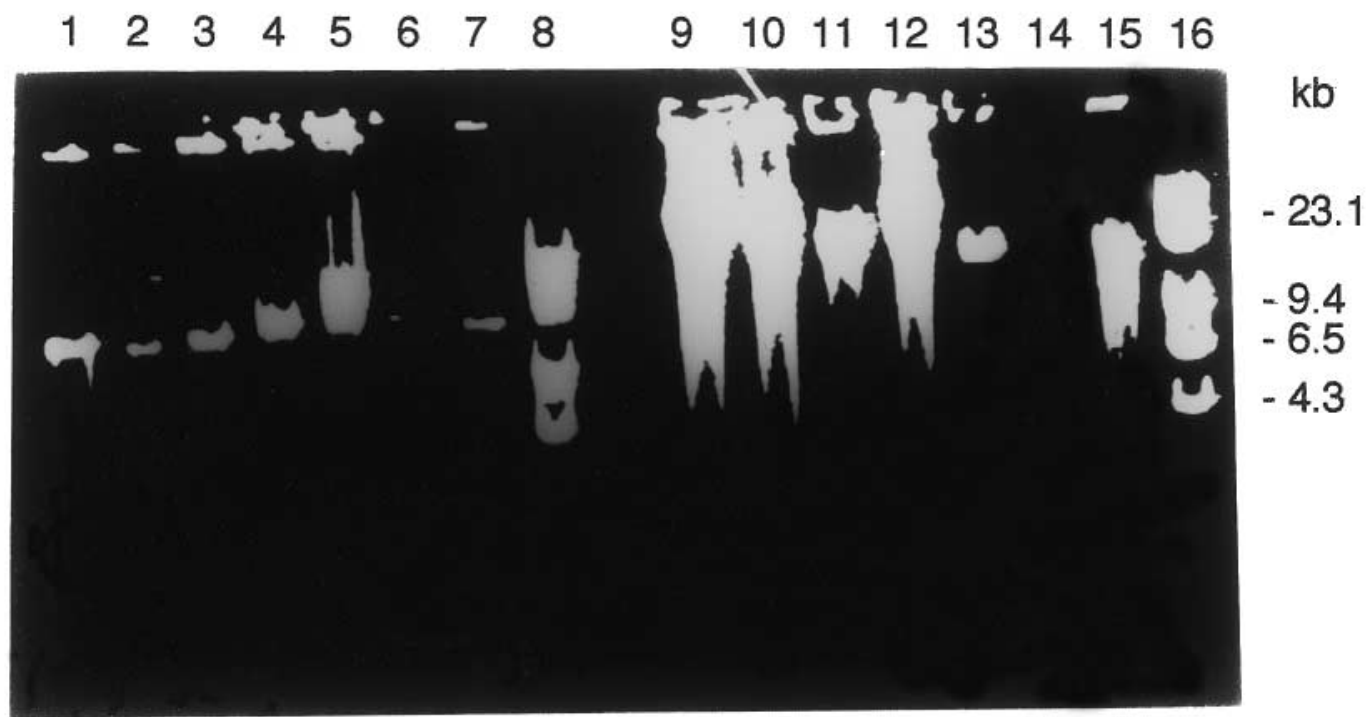

Fig. 1. Agarose $(0.7 \%)$ gel electrophoresis of lysates of non-tuberculous mycobacteria indicating the presence of a DNA band with an approximate size of $18 \mathrm{~kb}$. Lane 1, M. bovis; 2, M. kansasii, 3, M. smegmatis; 4, M. microti; 5, M. intracellulare; 6, M. xenopi; 9, M. gordonae; 10, M. bovis $(B C G) ; \mathbf{1 1}, M$. fortuitum; 12, M. avium; 13, M. phlei; 14, M. simiae; 7, 15, M. tuberculosis H37Rv; 8, 16, size markers (HindIII digest of $\lambda$ DNA). 


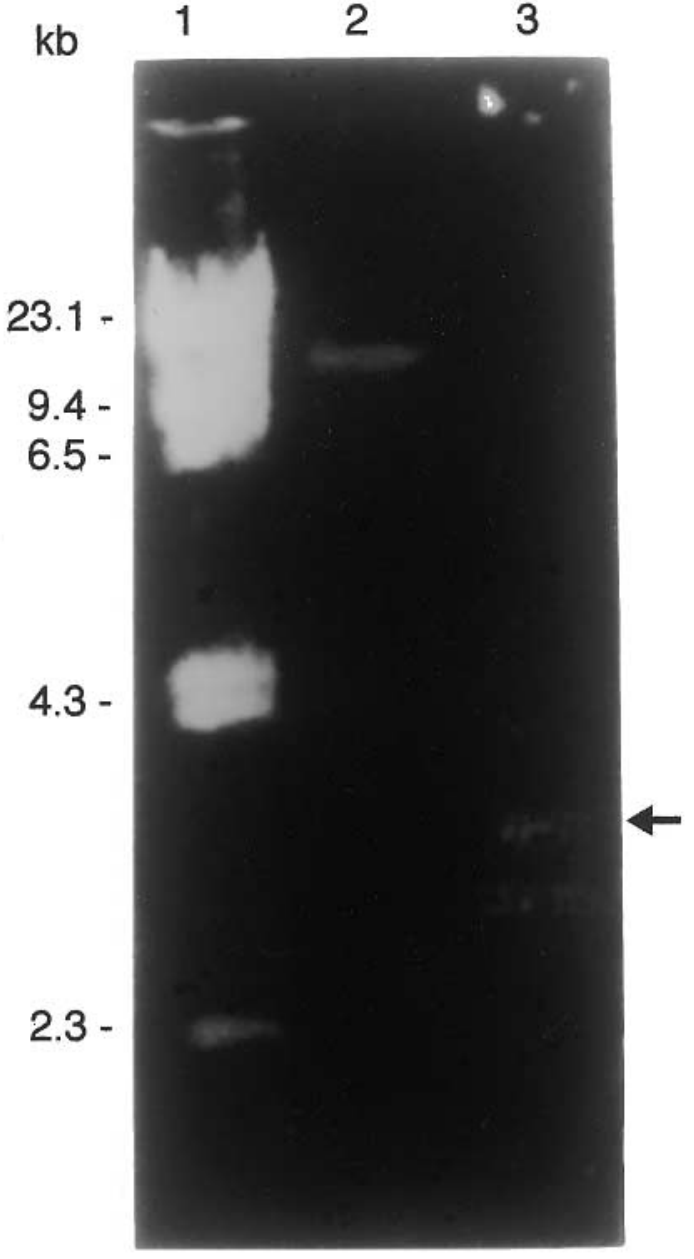

Fig. 2. Agarose $(0.7 \%)$ gel electrophoresis of plasmid DNA preparation by the modified method of Babu and Rajamanickam [3], wherein chromosomal DNA and RNA had been selectively eliminated by using $1 \mathrm{M}$ sodium acetate and $100 \mathrm{mM} \mathrm{MgCl}_{2}$ respectively. Lane 1, Hin dIIIcleaved $\lambda$ DNA as mol. wt marker; 2, M. tuberculosis H37Rv; 3, Escherichia coli used as a control indicating (arrow) closed circular DNA and no contamination of chromosomal DNA in the preparation.
Muralidhar K. Katti, Department of Microbiology, Sree Chitra Tirunal Institute for Medical Sciences \& Technology, Thiruvananthapuram - 695 011, India

\section{References}

1. Dam T, Bose M, Isa M, Virdi JS. Isolation of plasmids from Mycobacterium avium-intracellulare (MAC) strain from India. J Med Microbiol 2000; 49: 392-393.

2. Crawford JT, Bates JH. Isolation of plasmids from mycobacteria. Infect Immun 1979; 24: 979-981.

3. Babu GJ, Rajamanickam C. An improved method for the isolation of supercoiled plasmid DNA. Curr Sci 1998; 74: $572-573$.

\section{Dr M. Bose replies:}

The communication from us that was published as correspondence was originally submitted as a short report with photographs of electron microscopy and restriction digestion.

The plasmid (pLR7) in strain LR113 as reported by Crawford and Bates [1] is $15.3 \mathrm{~kb}$ in size and the origin of replication region of that plasmid has already been sequenced [2]. We had done hybridisation experiments designing an oligoprobe from the 'ori' of pLR7 and obtained signals from our plasmid $(24 \mathrm{~kb})$.

It is not always easy to work with wild plasmids. We shall struggle on and we shall be happy to communicate the results of further characterisation at the earliest opportunity.

\section{References}

1. Crawford JT, Bates JH. Isolation of plasmids from mycobacteria. Infect Immun 1979; 24: 979-981.

2. Beggs ML, Crawford JT, Eisenach KD. Isolation and sequencing of the replication region of Mycobacterium avium plasmid pLR 7. J Bacteriol 1995; 177: 4836-4840. 